\title{
Comparison of patterns of sexual assault among male victims during and after civil strife in Sri Lanka
}

\author{
Vidanapathirana $\mathrm{M}^{1 *}$, Tennakoon $\mathrm{A}^{2}$, Amararatne RRGS ${ }^{2}$, Gunawardene $\mathrm{S}^{3}$, Rathnaweera RHAI ${ }^{4}, \mathrm{Ratnayake}^{2}$
}

\begin{abstract}
Introduction: After the defeat of terrorism in May 2009, a significant change in the pattern of crime has been observed in Sri Lanka. Further, no in-depth studies have been conducted on male victims of sexual assault. This study was conducted to describe the nature of injuries and characteristics of male victims of sexual assaults during civil strife and compare those with after civil strife. Methods: A cross-sectional study on male victims of sexual assault was conducted at selected tertiary care hospitals in Sri Lanka. All Medico-legal examination forms (MLEFs) of 6 consented forensic medical practitioners covering 10 year period from May-2004 to May-2014 were studied.

Results: Of all the MLEFs (31,210), 102 (0.3\%) were male victims of sexual assault. Ages ranged from 03 to 36 years and 68\% were 10-19 years of age. Ninety four percent had no injuries. Thirty five percent occurred during civil strife and $65 \%$ after it. The circumstances such as time, place, perpetrator and number of incidents had significant difference with the period of occurrence $(\mathrm{p}<0.05)$. After civil strife, the referrals to the psychiatrist showed a significant difference $(\mathrm{p}<0.05)$. Conclusions: During civil strife, sexual assaults occurred at daytime, outside home, by non-relatives and multiple times. After civil strife, sexual assaults occurred during night, at home, by relatives and one episode. There was no significant difference in the nature of sexual acts. Significant increase in male sexual assaults at home by relatives after civil strife needs further investigations in order to develop evidence based interventions. (Words 241)
\end{abstract}

Key words: male sexual assault, during terrorism, after terrorism, medico-legal study

\section{Introduction}

After the defeat of terrorism in May 2009, a significant change in the social, cultural, political life as well as criminal activity patterns in Sri Lanka has been observed. Especially, male victims of sexual assault have emerged as a subject of public discussion in the recent years.

${ }^{1}$ Senior Lecturer, Department of Forensic Medicine, Faculty of Medical Sciences, University of Sri Jayewardenepura, Sri Lanka, ${ }^{2}$ Institute of Legal Medicine and Toxicology, Colombo, Sri Lanka, ${ }^{3}$ Department of Forensic medicine and toxicology, faculty of medicine, University of Colombo, Sri Lanka, ${ }^{4}$ Department of Forensic Medicine, Faculty of Medicine, University of Ruhuna, Sri Lanka

*Corresponding author: Vidanapathirana M, Tel: 0094772988227, e-mail address: mudithavidana@sjp.ac.lk, Fax: 0094112801480
Though a reckoning number of studies have been done on sexual assault of female victims, in-depth study on male sexual assault victims are hardly performed. There are no reported studies regarding sexual assaults against male victims comparing situation during and after civil strife in Sri Lanka. Sexual offenses are an important global health problem threatening people of all age groups. Such assaults not only affect the health of the victims but also have negative impact on development of the country. Therefore, forensic medicine services rested with a responsibility of initiating multidisciplinary approach to prevent, investigate, and manage this problem.

This study was conducted to describe the nature of injuries and characteristics of male victims of sexual assaults during the period of civil strife and compare those with after civil strife. 


\section{Methods:}

A retrospective cross-sectional study on male victims with sexual assaults was conducted at selected tertiary care hospitals (three out of nine) in Sri Lanka. All Medico-legal examination forms (MLEFs) from 6 consented forensic medical practitioners covering 10 year period from May 2004 to May 2014 were screened and 102 male victims of sexual assault were identified.

The five year period from $19^{\text {th }}$ May 2004 to $19^{\text {th }}$ May 2009 was considered as "during civil strife" period and the 5 year period from $20^{\text {th }}$ May 2009 to $19^{\text {th }}$ May 2014 was considered as the "after civil strife" period.

The forensic medical practitioner routinely records the demographic data and details of the incident obtained from victims on the MLEF. Further, the referrals to relevant specialists and their opinions are also documented. The relevant information was collected on to a data collection form.
When classifying the incidents according to the area of occurrence, those occurred in municipal council areas were considered as urban and the other areas were considered as rural.

For categorical variables, frequencies were calculated. $\mathrm{Chi}^{2}$ test was performed to examine the associations between categorical variables and pvalue $<0.05$ was considered statistically significant. The SPSS version 19 was used in statistical calculations. Permission for the research was obtained from the Directors of the relevant hospitals.

\section{Results:}

Among the MLEFs perused (31,210), there were 102 $(0.3 \%)$ male victims of sexual assault. According to the period of occurrence, $35 \% \quad(n=36)$ were during civil strife and $65 \%(n=66)$ were after civil strife. Majority $(88 \%, \mathrm{n}=90)$ were Sinhalese, 8 were Muslims and 4 were Tamils.

The area of living and age of male victims of sexual assaults during and after civil strife and their statistical associations are shown in Table 1.

Table 1: 'Area of living' and 'Age' of male victims of sexual assaults occurred during and after terrorism and their statistical associations

\begin{tabular}{|c|c|c|c|c|c|}
\hline & & $\begin{array}{c}\text { During terrorism } \\
\mathrm{n}(\%)\end{array}$ & $\begin{array}{l}\text { After terrorism } \\
\mathrm{n}(\%)\end{array}$ & $\begin{array}{l}\text { Total } \\
\mathrm{n}(\%)\end{array}$ & $P$ value \\
\hline \multirow[t]{2}{*}{ Area } & Urban & $26(72)$ & $40(61)$ & $66(65)$ & $0.241>0.05$ \\
\hline & Rural & $10(28)$ & $26(39)$ & $36(35)$ & \\
\hline \multirow[t]{2}{*}{ Age } & Child & $27(75)$ & $58(88)$ & $85(83)$ & $0.095>0.05$ \\
\hline & Adult & $9(25)$ & $8(18)$ & 17 (17) & \\
\hline
\end{tabular}

Regarding the area of living, $65 \%(\mathrm{n}=66)$ were from urban areas. Of them, $72 \%(\mathrm{n}=26)$ of during and $61 \%$ $(n=40)$ of after civil strife period were from urban areas but this association was not significant $(\mathrm{p}=0.241>0.05)$.

Ages of the male victims were ranged from $03-36$ years $($ mean $=13$ years and SD $+/-05$ years). Eighty three percent $(n=85)$ were children under the age of 18 years and $17 \%(n=17)$ were adults. Of them, $68 \%$ were between 10-19 years of age. Seventy-five percent $(75 \%, \mathrm{n}=27)$ of during civil strife and $88 \%$ $(\mathrm{n}=58)$ of after civil strife were children under the age of 18 years but this association was not significant $(\mathrm{p}=0.095>0.05)$.

The circumstances of the incidents of sexual assaults such as time, place, perpetrator and number of episodes were compared with the period of occurrence and their statistical associations are shown in Table 2. 
Table 2: Comparison of time, place, perpetrator and number of incidents with the period of occurrence and their statistical associations

\begin{tabular}{|c|c|c|c|c|c|}
\hline & & $\begin{array}{c}\text { During civil strife } \\
\mathrm{n}(\%)\end{array}$ & $\begin{array}{c}\text { After civil strife } \\
\mathrm{n}(\%)\end{array}$ & $\begin{array}{c}\text { Total }(\mathrm{N}=102) \\
\mathrm{n}(\%)\end{array}$ & $P$ value \\
\hline \multirow[t]{2}{*}{ Time } & Day & $34(94)$ & $53(80)$ & $87(85)$ & $0.049<0.05$ \\
\hline & Night & $02(06)$ & $13(20)$ & $15(15)$ & \\
\hline \multirow[t]{2}{*}{ Place } & At home & $01(03)$ & $21(32)$ & $22(22)$ & $0.000<0.05$ \\
\hline & Outside & 35 (97) & $45(68)$ & $80(78)$ & \\
\hline \multirow[t]{2}{*}{ Perpetrator } & Relative & $02(06)$ & $23(35)$ & $25(24)$ & $0.001<0.05$ \\
\hline & Non-relative & $34(94)$ & $43(65)$ & 77 (76) & \\
\hline \multirow[t]{2}{*}{ Episodes } & One & $24(68)$ & $58(88)$ & $82(80)$ & $0.010<0.05$ \\
\hline & Multiple & $12(32)$ & $08(12)$ & $20(20)$ & \\
\hline
\end{tabular}

Regarding the time of incidents, $85 \% \quad(\mathrm{n}=87)$ occurred during day time; during civil strife $94 \%$ $(\mathrm{n}=34)$ and after civil strife period $80 \%(\mathrm{n}=53)$ and this difference was statistically significant $(\mathrm{p}=0.049<0.05)$. After civil strife, the incidents tend to occur at night.

According to the place where the incident took place, $78 \%(\mathrm{n}=80)$ occurred at an outside place and the remaining incidents $(22 \%, \mathrm{n}=22)$ occurred at the victim's home. Three percent $(03 \%)$ during civil strife and 32\% after civil strife were taken place at home and this difference was statistically significant $(p=0.000<0.05)$. After civil strife, there was higher chance of incidents to occur at home.

The types of perpetrators were relatives $(25 \%, \mathrm{n}=25)$ and rest $(75 \%, \mathrm{n}=77)$ were non-relatives (known nonrelative $\mathrm{n}=69$ and unknown $\mathrm{n}=08$ ). Of this incidents, $06 \%$ of during civil strife and $35 \%$ of after civil strife were committed by a relative and this difference was statistically significant $(p=0.001<0.05)$. After civil strife, relatives had a higher chance of committing such assaults.

Regarding the number of episodes committed on a victim, $80 \%(n=82)$ suffered one episode and the remaining $20 \%(\mathrm{n}=20)$ had two or more episodes. Sixty seven percent $(67 \%)$ during civil strife and $88 \%$ after civil strife, had faced single episodes and this difference was statistically significant $(\mathrm{p}=0.010<0.05)$. After civil strife, there was a higher tendency to face single episodes.

There were two types of sexual assaults; nonpenetrative and penetrative. The non-penetrative sexual assaults found were 'showing genitals of perpetrator', 'touching the perpetrator's genitals', 'touching or sucking the victims' genitals and intercrural intercourse. The penetrative sexual assaults include oral and/or anal intercourse. 
The nature of the sexual acts was compared with the

penetrative sexual assaults and their statistical period of occurrence. Type of non-penetrative and associations are shown in Table 3.

Table 3: Type of the sexual act committed and the period of occurrence and their statistical associations

\begin{tabular}{|c|c|c|c|c|c|}
\hline Sexual act & & $\begin{array}{c}\text { During civil strife } \\
\mathrm{n}(\%)\end{array}$ & After civil strife & Total $(\mathrm{N}=102)$ & $\mathrm{P}$ value \\
\hline \multirow[t]{2}{*}{$\begin{array}{c}\text { Showing genital } \\
\text { organs }\end{array}$} & Yes & $01(03)$ & $05(08)$ & $06(06)$ & $0.420>0.05$ \\
\hline & No & $35(97)$ & $61(92)$ & $96(94)$ & \\
\hline \multirow[t]{2}{*}{$\begin{array}{l}\text { Touch perpetrator's } \\
\text { genitals }\end{array}$} & Yes & $03(08)$ & $07(11)$ & $10(10)$ & $1.000>0.05$ \\
\hline & No & $33(92)$ & $59(89)$ & $92(90)$ & \\
\hline \multirow[t]{2}{*}{$\begin{array}{l}\text { Touch victim's } \\
\text { genitals }\end{array}$} & Yes & $14(39)$ & $19(29)$ & $33(32)$ & $0.297>0.05$ \\
\hline & No & $22(61)$ & 47 (71) & $69(68)$ & \\
\hline Inter-crural & Yes & $31(86)$ & $51(77)$ & $82(80)$ & $0.283>0.05$ \\
\hline Intercourse & No & $05(14)$ & $15(23)$ & $20(20)$ & \\
\hline \multirow[t]{2}{*}{ Oral intercourse } & Yes & $05(14)$ & $17(26)$ & $22(22)$ & $0.164>0.05$ \\
\hline & No & $31(86)$ & $49(74)$ & $80(78)$ & \\
\hline \multirow[t]{2}{*}{ Anal intercourse } & Yes & $03(08)$ & $10(15)$ & $13(13)$ & $0.373>0.05$ \\
\hline & No & $33(92)$ & $56(85)$ & $89(87)$ & \\
\hline
\end{tabular}

None of the acts of sexual assaults such as exhibitionism, touching, inter-crural intercourse (IC), oral IC and Anal IC showed any significant association with the two periods of occurrence $(\mathrm{p}>0.05)$.
According to the examination findings, 94\% ( $\mathrm{n}=96)$ had no anal injuries. Fresh anal tears were found in four victims (Figure 1) and old scars (Figure 2) in two. Three were found in the upper half of the anus and other 3 in the lower half. None had oral or genital injuries. Two were subjected to non-sexual physical 
assaults such as punch and slap and were nongrievous blunt assaults. None had para-sexual injuries such as bite marks.

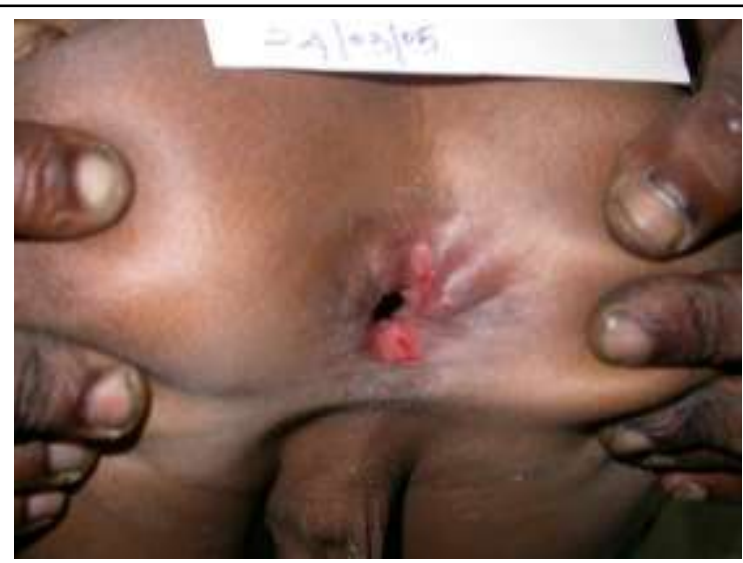

Figure 1: Anterior fresh anal tear

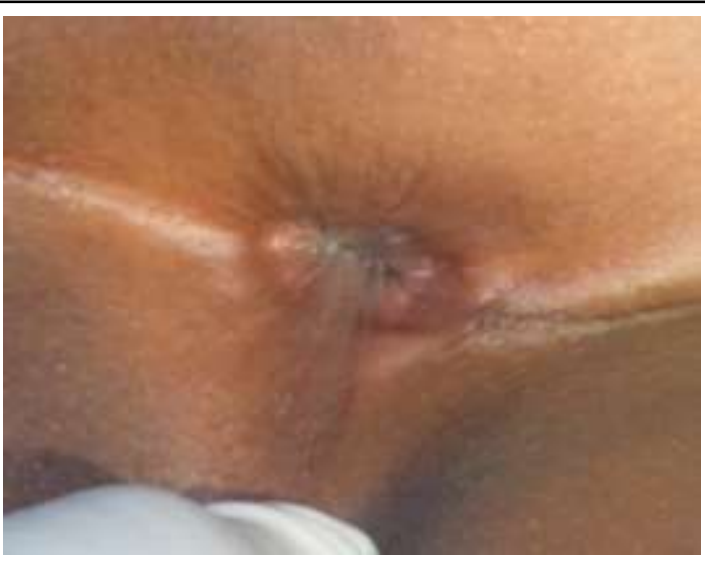

Figure 1: Posterior anal scar
Some victims had been referred to other specialists for further investigations and managements. Eighty five percent $(n=87)$ were referred to STD clinic for further management; during civil strife $81 \%(\mathrm{n}=29)$ and after civil strife $88 \%(\mathrm{n}=58)$.
Sixty three percent $(n=65)$ had been referred to the psychiatrist for counseling and management; during civil strife $47 \%(n=17)$ and after civil strife $73 \%$ $(\mathrm{n}=48)$. Sexually transmitted infection (STI) and psychiatric referrals in 2 periods of occurrence and their statistical associations are shown in Table 4.

Table 4: Type of referral of victims during 2 periods of occurrence and their statistical associations.

\begin{tabular}{|c|c|c|c|c|c|}
\hline & & During civil strife & After civil strife & Total $(\mathrm{N}=102)$ & \\
\hline & & $\mathrm{n}(\%)$ & $\mathrm{n}(\%)$ & $\mathrm{n}(\%)$ & I value \\
\hline STI referral & Yes & $29(81)$ & $58(88)$ & $87(85)$ & $0.318>0.05$ \\
\hline & No & $07(19)$ & $08(12)$ & $15(15)$ & \\
\hline Psychiatric referral & Yes & $17(47)$ & $48(73)$ & $65(64)$ & $0.010<0.05$ \\
\hline & No & $19(53)$ & $18(27)$ & $37(36)$ & \\
\hline
\end{tabular}

Regarding referrals to the psychiatrist, $47 \%$ during civil strife and $73 \%$ after civil strife were referred for counseling and management and this difference was statistically significant $(\mathrm{p}=0.049<0.05)$. There was a higher tendency to refer for counseling and management after civil strife. 


\section{Discussion}

Sri Lanka suffered from terrorism for more than 30 years and it has a deep impact on all aspects of Sri Lankan society. Hence, the cessation of terrorism in 2009-May and absence of violence would naturally have its repercussions on social life of the Lankan community and specifically on patterns of crime. In this study, it was found that there was a significant difference in the circumstances of the incidents of male sexual assaults during pre and post war era.

Sexual assaults on males are under reported by a very large margin as compared to females. About 3\% of American men have experienced an attempted or completed rape in their lifetime [1] but in this study it was $0.3 \%$. However, this study confined only to the victims who are reported to police. This low prevalence may have been mainly due to nonreporting of reckoning portion of incidents of sexual assaults to the police.

This study showed that the male children at their adolescence were at a higher risk and $68 \%$ were between 10-19 years of age. None of the races were immune and majorities $(90 \%)$ of the victims were Sinhalese because of the higher ratio of Sinhalese in Sri Lanka.

Similar to other crimes, the people living in urban areas were at higher risk $(65 \%)$ of male sexual assaults too.

Majority was non-penetrative sexual assaults and $80 \%$ were inter-crural intercourses. The penetrative assaults were oral intercourse $(22 \%)$ and anal intercourse $(13 \%)$. Few $(6 \%)$ had anal injuries and $2 \%$ were subjected to non-sexual physical assaults which were non-grievous. Further, the absence of oral, genital and para-sexual injuries was a significant finding among male victims.

The sexual assault victim has an increased risk of subsequent victimisation relative to an individual who was never victimised [2]. Similarly, in this study, $20 \%$ had faced multiple-episodes of sexual assaults with further victimizations. Therefore, the provision of holistic support for malevictims of sexual assault is regularly discussed in the literature [3].

According to the period of occurrence, majority $(65 \%)$ occurred after the civil strife. Further, there was a significant difference in the circumstance of the incidents during two periods. During civil strife period, the male sexual assaults occurred during day time, outside home by non-relatives and had faced multiple episodes. After the civil strife, it was found to be more during night, at home, by a relative and consisted a single episode incident. Further research is necessary to explain the above findings.

In penile vaginal penetration, the hymenal tears are usually found in the lower half of the hymen [4] but anal penetrations did not show such peculiar patterns. Study showed no significant difference in the nature of the sexual acts during the two periods.

In this study, the management of the victims comprised of routine referral to STI clinic and there was significant increase of psychological referral especially after the civil strife $(\mathrm{p}<0.05)$. Moreover, sexual assault is associated with posttraumatic stress disorder (PTSD) and related comorbidities [5]. Men may feel the need to withdraw from all sexual relationships for some time following the assault, they should be reassured that the assault does not change their personality or their sexual preference in any way [6]. In this study, it was revealed that $63 \%$ of victims were referred to psychiatrist for counseling and management. This management process should be improved up to multidisciplinary centres, especially dedicated to shelter-providing, information, counseling and victim support. This will also entail information and awareness campaigns for the general population, and the homosexual community in particular. Finally, we should not be afraid to envisage an investigation into this subject at an international level.

Finally, the findings of this study will assist in a greater understanding of circumstances associated with these assaults, aid in interventions to decrease their occurrence, and guide effective policymaking that will reduce all types of sexual assault among adolescents.

\section{Conclusions}

During civil strife, sexual assaults occurred during day time, outside home, by non-relatives for several episodes. After civil strife, the sexual assaults occurred during night, at home, by relatives and once. Further, the psychiatric referrals have been increased significantly after civil strife. However, there was no significant difference in the nature of sexual acts during the two periods. Presence of many similarities indicated that both groups learnt basis in a society that breeds violence. Significant increase of male sexual assaults at home by relatives after terrorism needs to be further investigated in order to develop evidence based interventions. 


\section{References}

1. National Institute of Justice and Centers for Disease Control \& Prevention. Prevalence, Incidence and Consequences of Violence Against Women Survey. 1998.

2. Lurie S, Boaz M, Golan A. Risk factors for rape revictimisation: a retrospective analysis. Journal of Obstetrics and Gynaecology. 2013 Nov; 33(8): 865-7.

3. Vidanapathirana M. Child sexual abuse; a medico-legal analysis.International Journal of Medical Toxicology and Forensic Medicine. 2014;4(3): 91-97
4. Darnell D, Peterson R, Berliner L, Stewart T, Russo J, Whiteside L, Zatzick D. Factors Associated With Follow-Up Attendance Among Rape Victims Seen in Acute Medical Care. Psychiatry. 2015;78(1):89-101. Doi: 10.1080/00332747.2015. 1015901.

5. Hiquet J, Gromb-Monnoyeur S, Men victim of sexual assault of concern into the first Emergency Medical Unit for Victims of Assaults in France. Journal of Forensic and Legal Medicine. 2013 Oct; 20(7): 836-41. 